\title{
Microanalysis of the structure of Carbon Cast Iron
}

\author{
Elena A. Chelnokova ${ }^{1}$, Olga I. Vaganova ${ }^{2}$, Zhanna V. Smirnova ${ }^{3}$, Maxim M. Kutepov ${ }^{4}$, Anna V. Lapshova ${ }^{5}$ \\ ${ }^{1}$ Minin Nizhny Novgorod State Pedagogical University, Nizhny Novgorod, Russia, chelnelena@ gmail.com \\ ${ }^{2}$ Minin Nizhny Novgorod State Pedagogical University, Nizhny Novgorod, Russia, vaganova_o@ rambler.ru \\ ${ }^{3}$ Minin Nizhny Novgorod State Pedagogical University, Nizhny Novgorod, Russia, \\ z.v.smirnova@mininuniver.ru \\ ${ }^{4}$ Minin Nizhny Novgorod State Pedagogical University, Nizhny Novgorod, Russia, kmm-asb@mail.ru \\ ${ }^{5}$ Minin Nizhny Novgorod State Pedagogical University, Nizhny Novgorod, Russia, any19.10@ mail.ru
}

\begin{abstract}
The research is aimed at studying the microstructure of white, gray, malleable and high-strength cast iron with different carbon content and establishing relationships between the composition, production conditions and structure of the studied cast iron. The microstructure of cast iron was examined using an optical microscope and a set of microshifts.
\end{abstract}

Key words: microanalysis, carbon cast iron, carbon, iron, mechanical mixture.

\section{INTRODUCTION}

Cast iron is used in various industries, in mechanical engineering, metallurgy, and others. To analyze their quality, both macroanalysis - analysis without special equipment, and microanalysis can be used. This article will consider the microanalysis of the structure of carbon cast iron. Cast iron is an iron-carbon alloy that contains from $2.14 \%$ to $6.67 \%$ carbon. High casting properties of cast iron «and its use as a casting alloy are due to the presence of eutectic in its structure. Carbon in cast iron is in two States:

- bound (as part of cementite Fe3C, ferrite and austenite);

- free (in the form of graphite)»[1].

Depending on this, white and gray cast iron are distinguished. Grey cast iron is the main material in mechanical engineering. It has high casting properties, has good sound and vibration-absorbing abilities. It has high anti-friction properties. It is also the least prone to thermal deformations during operation (unlike steel and aluminum alloys). It has a reduced sensitivity to surface defects. At the same time, it is worth noting that cast iron is well processed by cutting. Among the mechanical properties of cast iron, it is necessary to distinguish: strength;

-plasticity;

- elasticity;

- toughness;

- endurance.
It is worth saying that they are much lower than steel, but the choice of cast iron is due to their relative cheapness. "And in many cases they are used as substitutes for steel, and sometimes as the only possible material for use» [1].

«The chemical composition of gray cast iron can be:

- doped;

- unalloyed» [1].

«All elements contained in unalloyed gray cast iron (iron, carbon, silicon, manganese, phosphorus, sulfur) affect the conditions of graphitization, the number of graphite inclusions, the structure of the metal base and the properties of cast iron.

Carbon and silicon contribute to graphitization and determine the quality of cast iron, affecting the amount of graphite and casting properties. Manganese makes graphitization more difficult and improves the mechanical properties of cast iron. While sulfur and phosphorus on the contrary deteriorate mechanical properties» [1].

Alloyed cast iron in addition to the main elements (iron, carbon and silicon) includes alloying elements:

- chrome;

- aluminum;

- nickel;

- copper;

- molybdenum.

Their significant amount (more than 1\%) makes cast iron heat-resistant, heat-resistant, non-magnetic, with high corrosion resistance.

The microstructure of the metal matrix of gray cast iron in the equilibrium state is similar to the microstructure of steel with a carbon content of 0.01 to $0.8 \%$ and can be detected on etched microshlifs [1].

Graphite inclusions are clearly visible on non-etched sections at a magnification of 100 times.

White cast iron is cast iron in which all the carbon is located in a bound state. They have a specific Shine. «Their microstructure in the equilibrium state at room temperature is in full compliance with the lower part of the cast-iron section of the diagram» [1].

«The predominant phase of white cast iron is cementite. Therefore, their main properties are determined by the properties of this phase» [1]. 
The article discusses the microstructures of white, gray, malleable and high-strength cast iron with different carbon content.

\section{THEORETICAL FRAMEWORK}

To conduct the study, it is necessary to use a microscope that provides a detailed examination of objects. In this case, microanalysis is performed using a METAM LV microscope. It consists of the following nodes:

- footing;

- illuminator;

- guide with reflector;

- revolver with lenses ;

- focusing mechanism with a slide table;

phototubes;

- binocular attachment with eyepieces and video tube.

The object is placed in front of the lens, creating an enlarged and inverted image of the object. The image is located in front of the eyepiece, which creates an enlarged imaginary image of the object, which is located from the eyes of the researcher at the distance of the best vision $(\mathrm{D}=250)$ [2].

The magnification value of the microscope shows how many times the angle of view at which the observed objects are visible in the microscope is greater than the angle of view at which the ordinary eye sees the object under consideration at a distance of 250 millimeters [2].

The total magnification of the microscope is $\mathrm{V}=\mathrm{VOB} \cdot \mathrm{VOC}$, where VOB is the magnification of the lens, and VOC is the magnification of the eyepiece. It is worth noting that the magnification of the microscope cannot be unlimited [2].

For the study, a small sample is taken with a prepared surface for microanalysis (microchip).

Cast iron is called iron-carbon alloys that contain more than $2.14 \%$ carbon. Cast iron contains:

- carbon;

- iron;

- manganese;

- silicon;

- phosphorus;

- sulfur.

The combination of iron and carbon forms the following structures:

- austenite;

- ferrite;

- cementite;

- perlite;

ledeburite;

- graphite.

Austenite is a solid solution of carbon incorporation into iron. It has a low hardness, depending on temperature and carbon content, and has a high plasticity (50\%).

Ferrite is a solid solution of carbon incorporation into iron. Ferrite has a low hardness and high plasticity (50\%). When viewed with a microscope, the ferrite grains appear light, separated by a dark lattice of grain boundaries [3].

Cementite is a chemical compound of carbon and iron (iron carbide). It is characterized by high hardness and low plasticity. In chemical solutions, it is poorly exposed to etching. Under the microscope, it looks like light inclusions [3].

Perlite is a mechanical mixture (eutectoid) of ferrite with cementite, which is obtained as a result of the decomposition of austenite with $0.8 \%$ carbon [4]. Ferrite and cementite look like alternating plates. The hardness of perlite is 210 , plasticity is $15 \%$ [5]. Etched perlite under a microscope looks darker than ferrite [6]. At sufficiently large magnifications, perlite is observed as alternating dark (cementite) and light (ferrite) plates [7].

Ledeburite is a mechanical mixture (eutectic) consisting of austenite or perlite grains with cementite [8].

It is formed from the liquid phase when it is cooled to a temperature of $1147^{\circ} \mathrm{C}$. «At temperatures above $727^{\circ} \mathrm{C}$, the ledeburite structure is a mechanical mixture of austenite and cementite [9]. At temperatures below $727^{\circ} \mathrm{C}$, the structure is a mixture of perlite» [18] and cementite. Ledeburite is both a very hard and very brittle structure, because it contains very little cementite. After etching, ledeburite under a microscope looks like light areas of cementite with dark spots of perlite [10].

Graphite is a chemically pure carbon, has a hexagonal lattice and low mechanical properties [11]. Therefore, in the metal structure of cast iron, from the point of view of strength characteristics, graphite inclusions can be considered as voids [12]. However, graphites have played a positive role in the composition of caiguna:

- increase wear resistance and anti-friction properties of cast iron (acting as a dry lubricant);

- improve the machinability of cast iron by cutting [3].

- contribute to increasing the damping ability of the alloy (dampens vibrations).

The form of graphite inclusions (gray cast iron) is:

- with plate graphite (ordinary grey cast iron). It has fairly large graphite inclusions of rosette-shaped and petal forms, which look like plates or scales under the microscope);

- with vermicular graphite inclusions (they look like short worm-like veins);

- malleable grey cast iron (graphite inclusions in the form of flakes, evenly distributed in the matrix);

- «high-strength grey cast iron (includes graphite in the form of spherical inclusions or drops that are evenly distributed in the matrix)»[1].

The mechanical properties of cast iron depend on the type of metal base.

\section{RESULTS AND DISCUSSION}

The aim of the study is to study the microstructure of white, gray, malleable and high-strength cast iron with different carbon content. It was also necessary to establish the relationship between the composition, production conditions and structure of the studied cast iron.

The following materials and tools were used for the research: - metallographic microscope;

- a set of micro-grinders of white, malleable, grey and high-strength cast iron in two States:

- etched;

"untraveled."

- Atlas of microstructures. 
In white cast iron, carbon is bound (in the form of cementite $(\mathrm{Fe}, \mathrm{C}))$. White cast iron is divided into:

- pre-eutectic (from $2.14 \%$ to $4.3 \% \mathrm{~S}$ );

- eutectic $(4.3 \% \mathrm{~S})$;

- overeutectic (from $4.3 \%$ to $6.67 \%$ C) [13].

The structure of the pre-eutectic type of cast iron (represented by G. V. Klevtsov) is shown in figure 1 [3].

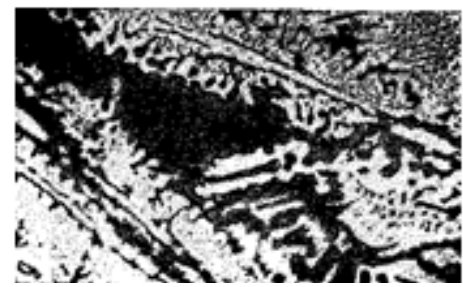

Figure 1: Microstructure of pre-eutectic white cast iron

The structure of eutectic white cast iron (represented By G. V. Klevtsov) is shown in figure 2 [3].

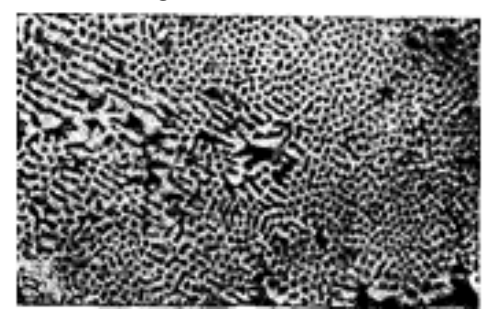

Figure 2: Microstructure of eutectic white cast iron

This microstructure includes only ledeburite, which is formed at $1147^{\circ} \mathrm{C}$ during eutectic crystallization of a liquid alloy containing $4.3 \%$ carbon. The peculiarity of eutectic at temperatures above $727^{\circ} \mathrm{C}$ is the fact that it consists of cementite and austenite with a content of $0.8 \%$ carbon. If the temperature of austenite exceeds $727^{\circ} \mathrm{C}$ - it turns into perlite. So after complete cooling, the structure of ledeburite includes cementite and perlite.

The structure of eutectic white cast iron (represented by G. V. Klevtsov) is shown in figure 3 [3].

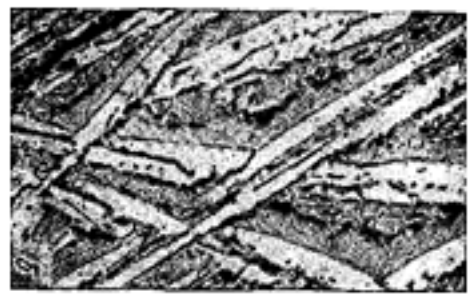

Figure 3: The microstructure of a hypereutectic white cast iron

The microstructure of a hypereutectic white cast iron includes ledeburite and primary cementite.

Devechinskogo in the microstructure of white cast iron (after complete cooling) includes:

ledeburite;

-perlite;

- secondary cementite.

The microstructure of white cast iron after cooling (represented by G. V. Klevtsov) is shown in figure 4 [3].

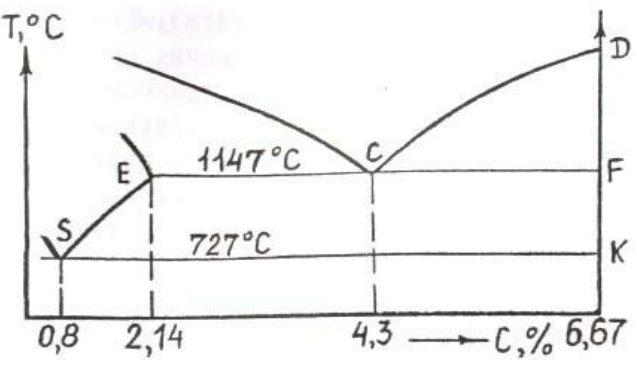

Figure 4: Microstructure of white cast iron after cooling

Secondary cementite in white cast iron with a low carbon content is clearly detected, since they have little ledeburite. In the process of increasing the carbon content, secondary cementite in the structure merges with ledeburite cementite. Therefore, we can say that the structure of such white cast iron consists of ledeburite and perlite.

The chemical composition of gray cast iron contains an increased content of silicon. When viewed in a microscope on a microplate of non-etched gray cast iron, it is possible to consider inclusions of plate graphite (figure 5, presented by $\mathrm{G}$. V. Klevtsov) [3].

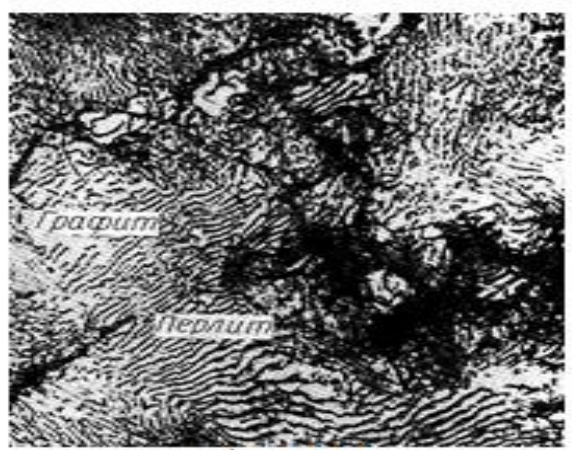

Figure 5: The microstructure of pearlitic grey cast iron

The size and location of graphite inclusions depends on the chemical composition of cast iron, its cooling rate, temperature and holding time of molten cast iron before casting, and other factors [14].

For example, graphite plates decrease with increasing cooling rate of molten cast iron [15].

Depending on the bound carbon, the metal base in cast iron can be:

- ferritic;

- ferrite-perlite;

- pearlitic.

The forms of graphite inclusions can be:

- lamellar;

- flocculent;

- spherical [16].

Ductile iron is produced from white cast iron using special graphitized annealing at temperatures of $950^{\circ}-1000^{\circ} \mathrm{C}$ [17]. After this annealing, cementite $(\mathrm{Fe}, \mathrm{C})$ as a metastable phase breaks down into austenite and graphite (carbon annealing). In ductile iron, carbon is formed as flake-like inclusions, which are clearly visible when viewed under a microscope. Depending on the mode of graphitizing annealing, the metal base of ductile iron can be ferritic, ferritic-perlite, or perlite. Therefore, there are three types of cast iron with the same name. 
Graphitizing annealing changes the mechanical properties of white cast iron.

Ductile iron, in contrast to white, is more ductile and durable. Giving graphite inclusions a rounded shape reduces the stress concentration before inclusions, which contributes to increasing the strength of cast iron.

This form of graphite is obtained by modification-the introduction of magnesium dust into molten cast iron $(0.03 \%$ $-0.7 \%$ of cast iron).

The metal base of high-strength cast iron includes the same types of structures as in the case of ductile and gray cast iron.

\section{CONCLUSION}

During the research, the microstructure of white, gray, malleable and high-strength cast iron with different carbon content was studied. The relationship between the composition, production conditions and structure of the studied cast iron was established. In ductile iron, carbon is formed as flake-like inclusions, which are clearly visible when viewed under a microscope. White cast iron is cast iron in which all the carbon is located in a bound state. They have a specific Shine. Grey cast iron has high casting properties, has good sound and vibration-absorbing abilities. It has high anti-friction properties. It is also less prone to thermal deformations during operation. It has a reduced sensitivity to surface defects.

\section{REFERENCES}

1. I.O.Dumansky, V.M. Alexandrov, V.L. Sytin. Microscopic analysis of carbon steel and cast irons in equilibrium state: method instructions for the implementation of the lab work on Materials Science, Arkhangelsk: NArFU, 22 p.2013 .

2. G. I. Leshchilovskaya. Materials science: laboratory practice for students of engineering specialties of higher educational institutions,Baranovichi: RIO BarGU, 2010. 96 p.

3. G.V. Klevtsov. Fractodiagnostics of the destruction of metallic materials and structures: textbook allowance, M.: MI-CC, pp. 264, 2007.

4. R.S. Akhmetkhanov. Application of computer technologies and the theory of fractals in the study of images of micro thin sections. Problems of machinery and automation, 3, 153-161. 2013.

5. Z.V. Smirnova, O.I. Vaganova, O.T. Cherney, E.V. Romanovskaya, N.S. Andryashina, D.S. Toshin, The organization of emergency and dispatching servicing of an apartment house. International Journal of Innovative Technology and Exploring Engineering 8(9), 1477- 1480, 2019.

https://doi.org/10.35940/ijitee.I8194.078919

6. A.Kh. Valiullin, M.N. Serazutdinov, S.G. Sidorin, F.S. Khairullin. Laboratory work on the course of resistance of materials: Method. directions / Kazan. nat. research technol. un-t; Comp.:A.Kh. Valiullin, M.N. Serazutdinov, S.G. Sidorin, F.S. Khairullin. Kazan, 64,2011 .
7. G.T. Klinkov. The specificity of manifestation of pedagogical communication as a special construct. Scientific Vector of the Balkans, 1, 51-52, 2018.

8. I.F. Filchenkova, Educational management of innovative activity of teachers as an object of pedagogical research.VestnikMininskogouniversiteta(Vestnik of Minin University), 2019. 7 (4), 3. (in Russ.).2019.

9. Z.V. Smirnova, A.A. Rudenko, O.I. Vaganova, O.T. Cherney, D.S. Mokerov, E.A. Semakhin, The research of carbon construction steel at laser alloying. International Journal of Innovative Technology and Exploring Engineering. 2019

10. V.F. Terentyev. About endurance limit of metal materials.New materials and technology and machine-upgraded. No. 1 pp. 32-38, 2007.

11. N.S. Abramova, O.I. Vaganova, L.I. Kutepova, Development of educational and methodological support in the context of the implementation of content and communication technologies.Baltiyskiygumanitarnyyzhurnal. Baltic Humanitarian Journal, 7, no. 2 (23), 181-184. 2018.

12. M.N. Bulaeva, O.I. Vaganova, M.N. Gladkova. Activity technologies in a professional educational institution.Baltiyskiygumanitarnyyzhurnal. Baltic Humanitarian Journal), 7, no. 3 (24), 167-170. 2018.

13. Zh.VSmirnova, O.T Cherney. Laser alloying technology when changing the processing speed. International Journal of Emerging Trends in Engineering Research, 8, no 4, 2020. https://doi.org/10.30534/ijeter/2020/40842020

14. N.A. Barkhatov, S.E. Revunov, Zh.V. Smirnova, O.T. Cherney M.V Mukhina. Recovery of gaps in records of Geomagnetic observatories by Neural Network. International Journal of Emerging Trends in Engineering Research, 8, no 4, 1243-1246, 2020. https://doi.org/10.30534/ijeter/2020/48842020

15. C. Santhosh, K. Hari Kishore, G. Pavani Lakshmi, G. Kushwanth, P. Rama Krishna Dharma, Teja, R. S. Ernest Ravindran, S. V. Cheerala, M. R. Kumar. Detection of Heavy Metal Ions using Star-Shaped Microfluidic Channel. International Journal of Emerging Trends in Engineering Research, 7, No. 12. 2019. https://doi.org/10.30534/ijeter/2019/067122019

16. A. Zakaria, M. S. N. Ibrahi, Experimental Evaluation of Multiple Savonius Turbines in Oblique and Cluster Configuration, International Journal of Emerging Trends in Engineering Research, 7, No. 12. 2019. https://doi.org/10.30534/ijeter/2019/10712201

17. A.V. Kirjukhin, O. O. Milman, A. V. Ptakhin, V. D. Kuprjashov, Efficiency of Schemes of Active Broadband Damping of Vibration Forces Transmitted by Vibration Insulation to the Foundation, International Journal of Emerging Trends in Engineering Research, 7, No. 12. 2019. https://doi.org/10.30534/ijeter/2019/017122019

18. L. A. Vinogradova, Yu.A. Kurganova. The structure of steels: textbook A. Vinogradov, - Ulyanovsk: UISTU, 54 p. 2009. 